\title{
Impactos de las tecnologías en la niñez
}

\section{Alejandra Tourn ${ }^{1}$}

\section{Aporte de estudiante}

Resumen: Las sociedades actuales se encuentra atravesada por la irrupción de nuevas tecnologías con alcances cada vez mayores con respecto a su uso y a sus funcionalidades. La innovación vertiginosa y constante de estas tecnologías, asociadas con el amplio despliegue de internet, en un mundo de por sí globalizado, ha facilitado el acceso de miles de millones de usuarios alrededor del plante. Con esto, el uso de tecnologías en entornos de red digitales y virtuales, se ha vuelto una parte importante de la vida diaria de las personas en su afán de lograr: entretenimiento, conectividad, acceso a información, entre otras cuestiones. En el presente trabajo se realiza un breve análisis sobre el impacto de las nuevas tecnologías en el mundo de la niñez. A continuación, se explora la implicancia del fenómeno respectivo a la utilización extendida de tecnologías por parte de niños y niñas con vistas a reflexionar sobre su potencialidad en la (re)conceptualización de la niñez, en tanto término que invita a comprender a aquellos sujetos como seres con voz, personas dignas de ser escuchadas y tenidas en cuenta, especialmente cuando se trata de un entorno sensiblemente familiar para ellos y ellas como lo es el de las herramientas tecnológicas.

La infancia es considerada un fenómeno histórico descubierto -en términos históricos- recientemente. Su identificación, como entidad específica y singular, se consolida en la segunda mitad del siglo XIX, especialmente entre las clases medias, para luego difundirse entre las clases trabajadoras en el siglo XX. Más tarde, empieza a ser valorada como parte de la estructura social, lo cual implica que pueda ser analizada desde dimensiones sociales antes impensadas, como pueden ser: la económica, la política o la psicológica. De esta manera, a la par del interés de la sociedad por los niños y las niñas, la perspectiva teórica tradicional sobre la infancia comenzó a ser desafiada.

Si bien la noción de infancia supo ser conceptualizada como una instancia previa a la adultez, en la época contemporánea se dio paso a un interés por las características propias de esta etapa vital de las personas. La ahora llamada niñez, pasó a ser comprendida con un peso específico que, tras el largo derrotero del siglo XX, empezó a considerar a los niños y a

\footnotetext{
${ }^{1}$ Estudiante de la carrera de Psicología, Universidad de Palermo (UP). Cursó sus prácticas de finalización de carrera en el Centro de Investigación en Ciencias Sociales de la UP (CICS-UP) durante el 2019. Correo electrónico: aletourn97@gmail.com
} 
las niñas como sujetos de derechos, dejando atrás la vieja noción de objetos de protección que recaía sobre ellos y ellas. El siglo XX, de hecho, fue anunciado como el Siglo del Niño y tiene su punto máximo en la Convención de los Derechos del Niño (de 1989), hito a partir del cual se alumbra un proceso sistemático por comprender, en su complejidad, a la niñez (Gaitán Muñoz, 1999).

Para Volnovich (2017) la concepción de la niñez es un fenómeno histórico, es decir, no meramente "natural", lo que obliga siempre a situar su conceptualización en tiempo presente. La etapa del capitalismo globalizado, donde la enorme expansión de la información contribuye a una comunicación global, hace que las tecnologías se reinventen, mejoren o se actualicen constantemente. En este sentido, vale decir que asistimos a un momento de cambio cultural que tiene a los "nativos digitales" (Volnovich, 2017), como protagonistas. Los nativos digitales serían los niños y las niñas que nacieron y crecieron en este contexto de rápido avance tecnológico; en el marco de una cultura signada por los cambios inverosímiles y muchas veces violentos, donde solo quienes sean formados en sus entrañas parecen ser capaces de dar respuestas adecuadas a los desafíos que se presentan.

Las nuevas generaciones están expuestas a todo tipo de tecnologías desde temprana edad, por lo cual el entorno mediatizado se vuelve algo común. Este grupo, llamado nativos digitales, está integrado por aquellos niños y aquellas niñas que comparten una cultura común y que tienen una apropiación tecnológica muy avanzada y dinámica, incluso mucho más que la de sus padres, con quienes se establece una brecha generacional muy marcada (ONU, 2014). Las pantallas están más presentes que nunca en todos los aspectos de la vida y, si bien antes, al hablar de pantallas, se hacía referencia solamente a la televisión, ahora se deben sumar las computadoras, los celulares y los videojuegos (entre otros gadgets) que son altamente utilizados por los niños y las niñas. $Y$ el Internet, en estos casos, es el responsable de las actividades que los niños y las niñas prefieren, especialmente los juegos en línea o las interacciones en distintas redes sociales (Pavez, 2014).

Con las diferentes herramientas tecnológicas se pueden realizar múltiples actividades, ya que sus potencialidades son francamente enormes. Se pueden utilizar en distintos momentos y lugares para diversos fines. Las tecnologías pueden ser positivas o negativas, es decir, la valoración de las mismas no depende de sus usos. Esto conlleva una serie de desafíos y riesgos a tener en cuenta.

Martino Gonzales (2014) explica que los beneficios que surgen en relación a su uso, por parte de niños y niñas, radica en que contribuyen al desarrollo del pensamiento crítico; especialmente cuando se trata del análisis, búsqueda y comparación de información. Con estas tecnologías ellos y ellas pueden aprender a realizar más de una tarea en simultáneo, por ejemplo: al tener muchas ventanas de internet en paralelo, con diferente contenido cada 
una, los chicos y las chicas se adecúan a un entorno de interactividad y trabajo múltiple. Asimismo, las tecnologías pueden ser fuentes de comunicación entre pares, contribuyendo a la socialización y a forjar identidades.

Por otro lado, también existen riesgos asociados al uso de tecnologías, algunos de ellos pueden ser el excesivo tiempo dedicado a la navegación por internet (lo que podría genera algún tipo de conductas adictivas), o bien el desarrollo de personalidades violentas 0 demasiado competitivas debido a los contenidos de combate en algunos videojuegos. Por otro lado, si bien existen softwares que sirven como filtros sobre el contenido que circulan en las redes, muchas veces se vuelve imposible impedir el acceso a pornografía, situaciones de violencia explícita u otro contenido que puede resultar traumático para niños y niñas. Además, hay un aspecto que agrava todas las situaciones antes mencionadas, y es que esta nueva generación se diferencia de los adultos que no conocen la mayoría de las herramientas, lo que contribuye a que los niños y las niñas cuestionen la autoridad, volviendo complicada la comunicación al momento de advertirles acerca de los potenciales riesgos.

Marciales Vivas y Cabra Torres (2010), por su parte, recopilan distintos estudios dedicados a la protección de niños y niñas dentro de la dinámica internet-niño. En este sentido, afirman que en el marco que ofrecen las tecnologías, surge una oportunidad para trabajar desde una lógica de orientación preventiva, con intervenciones en lugares académicos, para crear oportunidades educativas que permitan incluir a los más jóvenes en las discusiones acerca de las experiencias negativas y positivas del consumo de contenidos audiovisuales en internet.

El debate acerca de qué hacer en relación a los riesgos y beneficios de las tecnologías se ha tornado polarizado por argumentos que destacan la vulnerabilidad de las personas, especialmente de los niños y de las niñas, lo que conlleva -muchas veces- a prácticas sobreprotectoras. Pero, al mismo tiempo, las tecnologías aparecen como vías muy interesantes de inclusión, socialización e identificación de los más chicos, razón por la cual el uso responsable -y no excesivo- de las nuevas tecnologías podría estar contribuyendo al bienestar de este grupo poblacional. Se presenta así, entonces, el desafío de mantener un equilibrio entre la protección y el empoderamiento de los usuarios de tecnologías, especialmente de niños y niñas que son los más vulnerables (Pavez, 2014).

\section{Conclusiones}

El hecho de que la conceptualización de las diferentes etapas evolutivas de la vida humana sea una cuestión social e histórica que se produce en un momento y lugar determinado, y que difiere entre las diversas culturas, hace necesaria una revisión constante 
de las mismas. Actualmente, la vida del ser humano se encuentra atravesada por la globalización y el veloz alcance de las tecnologías que facilitan el acceso a información de manera inmediata, siendo necesario considerar este contexto al momento de analizar la vida cotidiana de las personas, especialmente cuando se revisan las dinámicas de uso de tecnologías. Los niños y las niñas, en particular, merecen especial atención en este sentido ya que se encuentran sumergidos en una paradoja: nacen en estos contextos de amplia dinamización tecnológica y son los principales personajes que conocen y manejan las tecnologías, pero, al mismo tiempo, ese contexto puede convertirse en una amenaza por la canalización de situaciones o contenidos potencialmente dañinos para ellos y ellas.

El entorno tecnológico y digital ofrece la posibilidad de sobrevolar la complejidad del ser niño y niña en el siglo XXI. Desde el espacio tecnológico y digital se alienta, de un modo casi natural, a que niños y niñas se expresen como protagonistas, por el simple motivo de que el uso de las nuevas tecnologías resulta una práctica ya interiorizadas por ellos y ellas desde el nacimiento, incorporando la usabilidad de gadgets como una rutina cotidiana. No obstante, al mismo tiempo, ese lugar de cotidianidad entre los más jóvenes, engendra el riesgo de convertirse en una real amenaza para ellos y ellas. Para una mayor complejidad, los adultos, frente a su impotencia en brindar protección, tienden a excesivas prohibiciones que, en la mayoría de las veces, terminan cercenando el despliegue de habilidades positivas entre los más jóvenes.

Al explorar los usos de la tecnología por parte de los niños y de las niñas se releva una nueva arena donde este grupo poblacional ve cuestionada la posibilidad de un despliegue pleno de su individualidad, en primera persona. Tanto por sobrecarga de acción o por total omisión de los estratos adultos, la experiencia de los más pequeños se ve limitada en su capacidad de ser tenidos y tenidas en cuenta, incluso en un marco que les resulta, intuitivamente, familiar.

\section{Referencias bibliográficas}

Gaitán Muñoz, L. (1999). Bienestar social e infancia: la distribución generacional de los recursos sociales. Intervención psicosocial, 8(3), 331-348.

Marciales Vivas, G. P., y Torres Cabra, F. (2010). Internet y pánico moral: Revisión de la investigación sobre la interacción de niños y jóvenes con los nuevos medios. Universitas Psychologica, 10(3), 855-865.

Martino Gonzales, F. M. (2014). Las tecnologías de información y comunicación y el bienestar psicológico en la generación net. Hamut'ay, 1(1), 39-51. 
Organización de las Naciones Unidas (ONU): Comisión Económica para América Latina y el Caribe (CEPAL), Fondo de las Naciones Unidas para la Infancia (Unicef) y Oficina Regional para América Latina y el Caribe (UNICEF TACRO) (2014). Derechos de la infancia en la era digital. Desafíos. Boletín de la infancia y adolescencia sobre el avance los Objetivos del Desarrollo del Milenio, (18) septiembre. Santiago de Chile. Recuperado de https://www.cepal.org/es/publicaciones/tipo/boletin-desafios/18

Pavez, M. I. (2014). Los derechos de la infancia en la era de Internet: América Latina y las nuevas tecnologías. Serie Políticas Sociales, № 210. Proyecto Fondo de las Naciones Unidas para la Infancia (Unicef) y Comisión Económica para América Latina y el Caribe (CEPAL). Recuperado de https://www.cepal.org/es/publicaciones/37049-derechos-la-infancia-la-era-internetamerica-latina-nuevas-tecnologias

Volnovich, J. (2017) Crecer y aprender en contextos digitales. En A. Kaplan y M. Sanmartín (Comp.), Niños dispersos, aburridos, solos. Nuevos contextos. El rol del adulto hoy (pp. 23-38). Colección Ensayos y Experiencias. Buenos Aires: Noveduc. 